\title{
FIRST IN-DEPTH ANALYSIS OF ENTERPRISE ARCHITECTURES AND MODELS FOR HIGHER EDUCATION INSTITUTIONS
}

\author{
Felix Sanchez-Puchol ${ }^{1}$, Joan A. Pastor-Collado ${ }^{2}$, and Baptista Borrell ${ }^{3}$ \\ ${ }^{1}$ Open University of Catalonia (UOC) \& SEIDOR SBS Services, Rambla del Poblenou 156, 08018 \\ Barcelona \\ ${ }^{2}$ Technical University of Catalonia (UPC), Department of Service and Information System Engineering, \\ Campus Nord - Edifici $\Omega$. C/ Jordi Girona, 1-3, 08034 Barcelona \\ ${ }^{3}$ SEIDOR SBS Services, C/ Pujades $350-6^{\text {th }}$ floor, 08019 Barcelona
}

\begin{abstract}
Enterprise Reference Architectures (ERAs) and Reference Models (RMs) have emerged over the last years as relevant instruments for improving the quality and effectiveness of enterprise architecture (EA) practice. Whilst a wide variety of different ERAs and RMs have been proposed for different industries and types of business, only few of them have been devoted to the Higher Education (HE) sector. In this paper, we propose an in-depth analysis process which we then critically apply to review, compare and classify 20 existing ERAs and RMs targeted to the HE domain. Our process uses a common set of 12 definitional attributes. In so doing, we contribute to the existing body of knowledge by providing a unified, structured and comprehensive analysis process and catalog of these abstract EA artifacts. With this we aim to create awareness on their potential practical utility and to increase their visibility, transparency and opportunity for their reusability by different HE stakeholders. Hence, the proposed process and catalog is expected to be useful both for practitioners and researchers by providing a panoramic view of more or less ready-to-use existing ERAs and RMs for HE, as well as a structure way to regard them. Moreover, and by specifying their main scope, coverage and extend of knowledge captured, the process and catalog might become a valuable tool for providing guidance to HE stakeholders on making better-informed decisions on the selection of suitable architectural artifacts for being conveniently adapted or applied in different EA practices conducted at their respective institutions.
\end{abstract}

\section{KEYWORDS}

Enterprise Reference Architecture, Reference Model, Enterprise Architecture, Higher Education, Review 


\section{INTRODUCTION}

Enterprise Architecture (EA) is currently considered as one of the main key instruments for Information Systems (IS) managers to cope with tensions between business demands and IS needs (Bischoff et al., 2014; Kotusev et al., 2015; Luftman et al., 2004). Over the last years, and as a specific type of EA artefact, Enterprise Reference Architectures (ERAs) and Reference Models (RMs) have emerged as relevant instruments for providing common understanding among different stakeholders, improving the effectiveness of EA practices and raising the quality of architectural designs (Niemi and Pekkola, 2017; Purao et al., 2011; Timm, 2018). A wide variety of heterogeneous ERAs and RMs have been defined by both industry and academia for specific classes of enterprises and business domains. Such efforts have mainly concentrated on rather service information-intensive industries and public services, as banking (Bonnie and Obitz, 2013), telecommunications (Czarnecki and Dietze, 2017), insurance (Huschens and Rumpold-Preining, 2006) eGovernment (E-Overheid, 2010) or defense (Department of Defense, 2010; Ministry of Defence, 2013), to cite a few.

Nonetheless, little work has been devoted into the development and design of such kind of artifacts tailored to be specifically applied in Higher Education Institutions (HEIs), where EA adoption has historically been considered as a complex and cumbersome issue (Luftman and Kempaiah, 2007; Syynimaa, 2015; JISC, 2009). Therefore, there still is a clear need to develop and foster "the feasibility of formalized frameworks and components of EA specifically tailored to suit the structure of HEIs" (Oderinde, 2010, p. 7). Furthermore, the current relevance of the topic has been recently noticed by several authors, stressing for example, the potential of EA practices and artefacts as facilitators for building and documenting internal quality assurance systems and practices in HEIs (Barata and Cunha, 2017; Olsen and Trelsgård, 2016, p. 808; Riihimaa, 2009). For exemple in Europe, due to the new regulatory reforms introduced by the Bologna Process (Manatos et al., 2017), these complex systems have become nowadays a critical artefact for HEIs governance (Campbell and Carayannis, 2016).

Aiming to bridge such gap, in this paper we extend our previous preliminary works (Sanchez-Puchol et al., 2017; Sanchez-Puchol and Pastor-Collado, 2017, Sanchez-Puchol et. al., 2018) by critically reviewing, analysing, comparing and classifying existing ERAs and RMs for HEIs. In so doing, we aim to contribute to the existing body of knowledge by (i) creating awareness on the HEI and IS communities about the potential practical relevance of such abstract models, (ii) by proposing a sound in-depth analysis process for such artefacts, and (iii) by providing a well-structured catalogue of existing artefacts in order to facilitate their visibility, transparency, comparison, classification and potential practical use for both practitioners and professionals in the higher education sector.

\section{BACKGROUND}

In this section we briefly define first the concepts of ERA and RM, as they represent the core research topic of our study. Although they tend to be sometimes used interchangeably, several nuances might be highlighted for each specific case (Angelov et al., 2012; Thomas, 2006). Next, we highlight previous research establishing taxonomies, classifications or comparative studies on similar types of artefacts, with the aim of getting initial insights to establish and propose our own in-depth analysis process for the purposes of the present work, as well as its application. 


\subsection{Reference Architectures, Reference Models and Enterprise Reference Architectures}

In general terms, Reference Architectures (RAs) have been defined by Lankhorst (2014) as "standardized architectures that provide a frame of reference for a particular domain, sector or field of interest (...) provid[ing] a common vocabulary, reusable designs and industry best practices". RAs leverage the reuse of knowledge by identifying, grouping and abstracting common features of a particular domain in an unique and a product/vendor-independent model, which in turn, acts as a reference for all the specific models of such domain (Angelov et al., 2012; Cloutier et al., 2010, p. 19). As abstract artefacts models (i.e. models of classes of objects), RAs should be conveniently specialized (i.e. instantiated) in order to obtain the model of a particular solution architecture (Cloutier et al., 2010; Lankhorst, 2014). Describing architectures has proven to be difficult, and therefore, they need to be conveniently documented and structured into manageable pieces, each one of which addresses a number of facets configuring the architecture (Greefhorst et al. 2006, pp.103-109). For instance, a RA can be characterized as a bundle or package of multiple architectural assets, which may include, among others: best practices, (architectural) design principles and reusable patterns, vocabularies, glossaries, technical standards as well as different conceptual models representing the targeted architectural or class-of-objects domain (Cloutier et al., 2010; Kotzampasaki, 2015; Lankhorst, 2014).

Given such background, RMs can be viewed as one of the core elements of a RA, since they particularly detail the specific scope and the level of specialization of the information provided (i.e. features, knowledge, etc.) to consider the scoped domain. In other words, RMs bring to table a clear and simple (usually on-a-single-page) view of the domain of interest, which can be then conveniently adjusted to suit better the particular needs of the RM's user (Pajk et al., 2012; Pang, 2015). Thus, RMs are generic conceptual models focussed on specific aspects of a certain problem - i.e. function, information, process, etc. - that formalize a set of generally accepted practices and encapsulate knowledge to be reused later in a particular application domain (Fettke and Loos, 2007). For instance, RAs tend to inherently be layered and partitioned artefacts as they usually incorporate more than just one RM, representing several (disjoint) partial views of a whole domain. Unfortunately, and due to their abstract and generic nature, not all existing RAs incorporate specific consistency patterns or viewpoints showing the interactions, dependencies and relationships among objects represented in each of their RM.

Lastly, ERAs emerge as a particular subtype of RAs, when the targeted domain is set to a "class of enterprises" (Timm, 2018, p. 209). Hence, they still encompass a high level of abstraction, but to a lesser extent than a RA. ERAs have been defined as " a generic EA for a class of enterprises, that in a coherent whole of EA design principles, methods and models which are used as foundation in the design and realization of the concrete EA that consists of three coherent partial architectures: the business architecture, the application architecture and the technology architecture" (ten Harmsen van der Beek et al., 2012, p. 99). Therefore, ERAs and RMs for HEIs represent the subset of those artefacts tailored for being used in higher education contexts. 


\subsection{Previous Relevant Analysis Proposals}

A plethora of studies conducting comparative approaches between diverse EA frameworks can be found in the literature. Without the aim of being exhaustive, we can emphasize, for example, the work by Magoulas et al. (2012) comparing EA frameworks in terms of architectural alignment dimensions; Rouhani et al. (2013) comparing EA frameworks in terms of concept concepts (i.e. definition, relationship among artifacts, etc.), modelling (i.e. notation, syntax, semantics) and processes (i.e. EA lifecycle) based attributes; Tang et al. (2004) comparing frameworks in terms of goals, inputs and outputs; Urbaczewski and Mrdalj (2006) comparing EA frameworks in terms of architectural views, abstractions and Systems Development Life Cycle encompassment; or even the work by Aljlayel (2016), who used EA generic layers defined by Winter and Fischer (2007) to perform his comparative between EA frameworks.

On the other hand, and adopting a rather narrower perspective, some authors focussed their work in the specific content of the EA frameworks studied. Hence, Alwadain et al. (2013) analyzed EA frameworks in terms of their integration of SOA elements (i.e. identification and relative position of SOA elements within the framework). Similarly, Masuda et al. (2016) compared EA frameworks in terms of their integration of Mobile IT/Cloud-related elements. Greefhorst et al. (2006) analyze more than 20 EA frameworks, and inductively derive and synthetize a list of 9 base dimensions for their classification, including their type of information, scope, detail level, stakeholders (audience), transformation, quality, meta-level, nature and representation. Finally, Timm et al. (2017) recently developed a complete Quality Framework for EA models based on 6 principles (validity, relevance, economic efficiency, systematic model structure and comparability) further decomposed into 25 different attributes.

There are also several studies developing taxonomies and comparative frameworks for Software Reference Architectures (SRAs), which represent another concrete sub-type of RA. Therefore, they can be a good reference point for identifying plausible attributes and properties for comparing different instances of concrete RAs. In this line, we can highlight the contribution by Angelov et al. (2012), who developed their SRA classification framework based on the previously referred contribution by Greefhorst et al., (2006) in the EA arena. Further, Nakagawa et al. (2014) proposed and extended a detailed framework for characterizing SRAs and also developed a reference model for SRA (RA-Model). Fettke et al., (2006) compared 30 different existing business process RMs grounding on 16 different criteria, considering facets related with their general characterization, construction and application. Finally, Mettler (2011) inductively developed a framework of decision parameters for analyzing and comparing generic maturity models grounding on their stages of development (designer's perspective) and application (user's perspective) based upon the author's experience of conceiving such kind of artefacts.

In sum, and given all the previous background, to the best of our knowledge no prior review has been yet undertaken to provide a comprehensible and comparative in-depth analysis of existing ERAs for HEIs, confirming thus the need as the novelty of our present contribution. 


\section{OUR PROPOSED IN-DEPTH ANALYSIS PROCESS}

Based on the prior analysis proposals, we have proposed the in-depth analysis processes explained in this section, and which consists in 3 main steps: 1) our identification of REAMs; 2) our framework for analysis, comparison and classification of REAMs; and 3) our application of the framework to the identified REAMs. For simplicity purposes, in the remaining of the paper we refer to them as Reference Enterprise Architecture Models (REAMs) for HE, regardless of their concrete nature as an ERA or as a RM.

\subsection{Our Identification of REAMs}

Grounding on previous literature reviews conducted by the authors (Sanchez-Puchol et al., 2017), a total of 20 relevant artefacts have been identified, critically analysed and classified. Six of them were considered as ERAs while the remaining 14 were viewed as rather RMs.

Table 1. Higher education REAMs analyzed in this paper

\begin{tabular}{|c|c|c|c|c|}
\hline Artefact Name & Abbreviator & Type & $\begin{array}{c}\text { Bibliographic Base } \\
\text { References }\end{array}$ & $\begin{array}{c}\text { Current } \\
\text { Status } \\
\end{array}$ \\
\hline $\begin{array}{l}\text { Hoger Onderwijs } \\
\text { Referentie Architectuur }\end{array}$ & HORA & ERA & $\begin{array}{c}\text { (SURF, 2013a, 2013b, } \\
\text { 2013c) }\end{array}$ & Active \\
\hline $\begin{array}{l}\text { ITANA Reference } \\
\text { Architecture for Teaching } \\
\text { and Learning }\end{array}$ & RATL & ERA & $\begin{array}{c}\text { (Abel et al., 2013; ITANA } \\
\text { Working Group, 2012) }\end{array}$ & Active \\
\hline $\begin{array}{l}\text { CAUDIT Enterprise } \\
\text { Architecture } \\
\text { Commons for Higher } \\
\text { Education }\end{array}$ & CAUDIT & ERA & (CAUDIT, 2016, 2017) & Active \\
\hline $\begin{array}{l}\text { The TIER (Trust and } \\
\text { Identity) Reference } \\
\text { Architecture }\end{array}$ & TIER & ERA & $\begin{array}{l}\text { (TIER-Data Structures and } \\
\text { APIs Working Group, 2016) }\end{array}$ & Active \\
\hline $\begin{array}{l}\text { Cloud Computing } \\
\text { Architecture for Higher } \\
\text { Education }\end{array}$ & CLOUD & ERA & $\begin{array}{l}\text { (Mircea and Andreescu, } \\
\text { 2011; Pardeshi, 2014) }\end{array}$ & Unknown \\
\hline $\begin{array}{l}\text { Common Enterprise } \\
\text { Architecture in the } \\
\text { Norwegian HE sector }\end{array}$ & NOR-EA & ERA & $\begin{array}{l}\text { (Bergh-Hoff et al., 2015; } \\
\text { Olsen and Trelsgård, 2016) }\end{array}$ & $\begin{array}{c}\text { Ongoing } \\
\text { (estimated) }\end{array}$ \\
\hline $\begin{array}{l}\text { UCISA UK HE Capability } \\
\text { Model }\end{array}$ & UCISA & $\mathrm{RM}$ & $\begin{array}{c}\text { (Anderson, n.d.; UCISA, } \\
\text { 2018) }\end{array}$ & Active \\
\hline $\begin{array}{l}\text { Colombian Higher } \\
\text { Education Enterprise } \\
\text { Architecture }\end{array}$ & $\mathrm{CHE}^{2} \mathrm{~A}$ & $\mathrm{RM}$ & $\begin{array}{c}\text { (Llamosa-Villalba et al., } \\
2014,2015)\end{array}$ & $\begin{array}{c}\text { Active } \\
\text { (estimated) }\end{array}$ \\
\hline $\begin{array}{l}\text { Charles Sturt Univ. HE } \\
\text { Business Process Reference } \\
\text { Model }\end{array}$ & CSU-BPM & $\mathrm{RM}$ & $\begin{array}{c}\text { (Charles Sturt University, } \\
\text { 2010) }\end{array}$ & $\begin{array}{c}\text { Closed } \\
\text { (estimated) }\end{array}$ \\
\hline $\begin{array}{l}\text { HE-IUP Business Process } \\
\text { Model }\end{array}$ & HE-IUP & $\mathrm{RM}$ & (Reiner, 2014) & Closed \\
\hline
\end{tabular}




\begin{tabular}{|c|c|c|c|c|}
\hline Artefact Name & Abbreviator & Type & $\begin{array}{c}\text { Bibliographic Base } \\
\text { References }\end{array}$ & $\begin{array}{l}\text { Current } \\
\text { Status }\end{array}$ \\
\hline $\begin{array}{l}\text { Business Process Reference } \\
\text { Model for HE }\end{array}$ & BPRM-HE & $\mathrm{RM}$ & $\begin{array}{l}\text { (Svensson and Hvolby, } \\
\text { 2012) }\end{array}$ & Unknown \\
\hline $\begin{array}{l}\text { Higher Education } \\
\text { Information Systems in } \\
\text { Croatia }\end{array}$ & HE-ISC & $\mathrm{RM}$ & (Frackmann, 2007) & Closed \\
\hline $\begin{array}{l}\text { The ICOPER (eContent+ } \\
\text { Best Practices Network) } \\
\text { Reference Model for } \\
\text { Outcome-based HE }\end{array}$ & ICOPER & $\mathrm{RM}$ & $\begin{array}{l}\text { (Pawlowski and Kozlov, } \\
\text { 2013; Simon et al., 2011) }\end{array}$ & Closed \\
\hline $\begin{array}{l}\text { Unified Information } \\
\text { Systems Reference Model } \\
\text { for HE Institutions }\end{array}$ & UISRM-HE & $\mathrm{RM}$ & $\begin{array}{c}\text { (Sanchez-Puchol et al., } \\
\text { 2017) }\end{array}$ & Active \\
\hline $\begin{array}{l}\text { e-education Application } \\
\text { Framework }\end{array}$ & eEdSF & $\mathrm{RM}$ & (Fagan, 2003) & Closed \\
\hline $\begin{array}{l}\text { Univ. of Tras-o-Montes e } \\
\text { Alto Douro } \\
\text { Multidimensional IS } \\
\text { Architecture } \\
\end{array}$ & UTAD-ISA & $\mathrm{RM}$ & (Bessa et al., 2016) & $\begin{array}{c}\text { Active } \\
\text { (estimated) }\end{array}$ \\
\hline $\begin{array}{l}\text { Reference Model of IS for } \\
\text { an Integrated Campus } \\
\text { Management }\end{array}$ & RMIS-ICM & $\mathrm{RM}$ & (Bick and Börgmann, 2009) & Closed \\
\hline $\begin{array}{l}\text { Reusable Process Model } \\
\text { Structure for HE }\end{array}$ & RPMS-HE & $\mathrm{RM}$ & (Van der Merwe, 2005) & Closed \\
\hline $\begin{array}{l}\text { Value Chain for Higher } \\
\text { Education }\end{array}$ & VC-HE & $\mathrm{RM}$ & (Hutaibat, 2011) & Closed \\
\hline $\begin{array}{l}\text { Reference Model of } \\
\text { University IT Architecture }\end{array}$ & UNITA & $\mathrm{RM}$ & (Chen et al., 2016) & $\begin{array}{c}\text { Active } \\
\text { (estimated) }\end{array}$ \\
\hline
\end{tabular}

\subsection{Our Framework for Analysis, Comparison and Classification of REAMs}

The comparative analysis framework (see Figure 1) has been conceived and inspired from previous highlighted literature devoted to create taxonomies or classifications for similar (model) artefacts, and particularly in the previously mentioned contributions by Fettke et al. (2006), Greefhorst et al., 2006), Angelov et al. (2012) and Mettler (2011). 


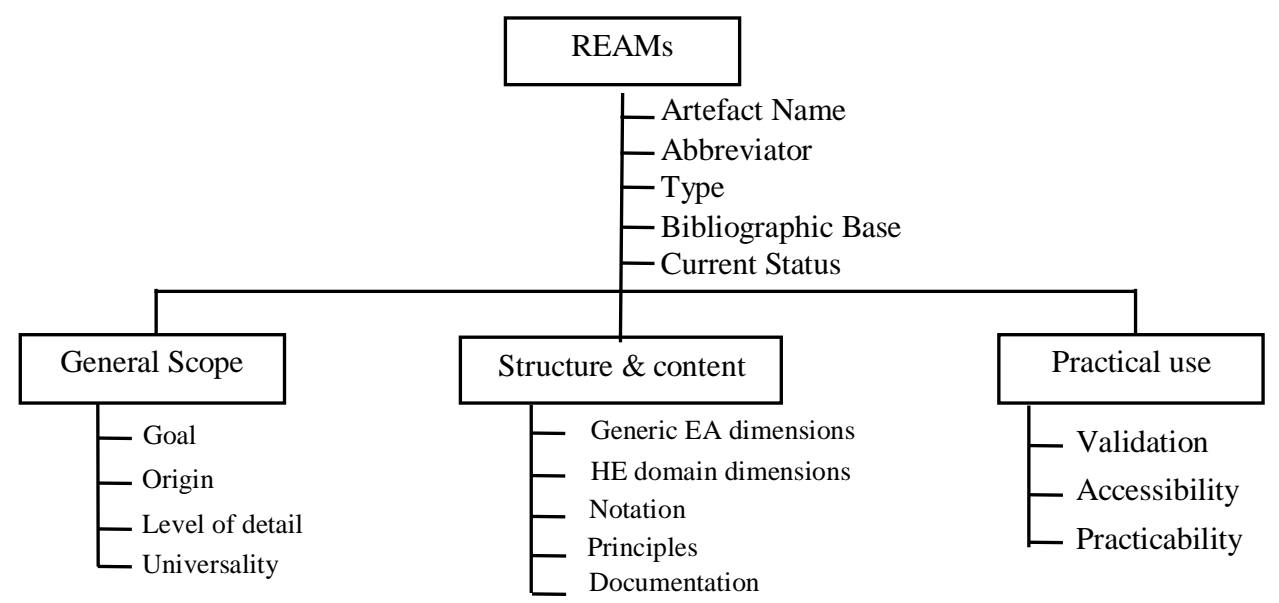

Figure 1. Criteria Framework used in this Paper for Investigating REAMs in HE

Next we provide descriptive information for each particular attribute configuring the framework. Multiple-values are possible for several of them, as they have not been defined to be mutually-exclusive in all cases.

- Identification. The identification of the artefacts is made by running numbers and their original name and the type of artefacts (ERA or RM). Bibliographic base references of the sources containing justificatory knowledge and information of the covered models is also provided. Finally, the current status indicates whether the development of the artefact model is in an active, ongoing, closed or unknown state.

- General scope. According to Cloutier et al. (2010), two main goals can be considered for the intended usage of a RA: standardization of a specific class of solution architectures (which in turn, may promote and enable the interoperability among systems/components considered by the model) or design facilitation of the specific solution architectures (providing guidelines and recommendations in the form of generic architectural principles, blueprints, patterns, etc.). The origin attribute reflects whether the artefact has its source from academia or practice. Similarly to Greefhorst et al. (2006), the level of detail reflects the concreteness and extent of information captured by the artefact. We consider three possible levels of detail, namely, detailed, semi-detailed and aggregated taking into account the number of elements defined in the REAM as well as the number of explicit aggregations levels used for its specification. Finally, the universality attribute reflects the generalizability of the particular artefact in terms of a HE system, which can be at general level, at regional or national level or at the particular scope of a unique HE settlement.

- Structure and content. The structure and content of a REAM can be inspected from the point of view of the generic domain levels of an EA- that is, business (i.e. processes, capabilities), IS (data and applications) and technology (Kotusev et al., 2015)- as well as from HE-oriented dimensions focussed in its main missions, that is, teaching and learning, research and development, support services and third mission (Manatos et al., 2017). In line with Angelov et al. (2012), the level of formalization regarding the content representation 
presented by an REAM is covered by the notation attribute. Three operational values are possible, unformal (by means of natural language or an ill-defined graphical notation), semiformal (using a well-defined notation, as UML or Archimate) or formal (based on a formal architecture specification language, strictly defining the semantics of the artefact). We also consider the explicit inclusion of architectural principles and the type of documentation available, in terms of a well-structured specification, a wiki/website, or an alternative form of documental/textual support (de Boer et al., 2011).

- Practical use. The practical utility of REAMs is assessed by considering three attributes. First, and regarding evaluation, we looked for the existence of usage evidences (i.e. tested vs unclear) of the operationalization of the artefact aiming to ensure or demonstrate (in some way or another) its practical utility or relevance. Next, the accessibility to the artefacts is analysed on the basis of three possible values, namely whether it is free for use (no barriers to accessing to the whole contents or existing documentation of the model), restricted (existence of some type of barrier for accessing the artefacts' documentation or any kind of license limiting its practical use) or charged (limited access to the model to an audience by means of a fee payment). Finally, we have reviewed whether the information provided by the artefact contains practical recommendations for how to use it in a situational HE context, in terms of guidelines, basic recommendations, or contrarily, if such information remains unclear.

\subsection{Our Application of the Framework to the Identified REAMs}

Results of the critical analysis performed on the uncovered REAMs are presented in Table 2 . Collectively, it can be concluded that there is a plethora of heterogeneous artefacts, conceived with different scope, focus, and levels of granularity and detail. Both researchers and practitioners can take advantage of the presented catalogue to choose those REAMs that suit better for their concrete duties in their respective HEI contexts. In terms of completeness, we must clearly highlight the potential of the Dutch's national HORA, which can provide support for a lot of activities and goals from a holistic perspective. Similarly, CAUDIT also ranks well is terms of completeness. However, it seems that it provides less practical support information than HORA and that is focussed on the business and data domain dimensions of an EA. There is also a good variety of business process-oriented and application-oriented RMs, but they tend to be defined at a very aggregate level of detail, which may complicate its applicability as they would have to be much customized. Finally, we found evidence on the existence of an initiative devoted to the development of a Norwegian national HE ERA. Nonetheless, we were not able to find clear evidence on its core structural components, and therefore, we only could partially evaluate it. Our suspicion is that it still is an on-going initiative. 
IADIS International Journal on Computer Science and Information Systems

Table 2. General Scope Attributes Analysis

\begin{tabular}{|c|c|c|c|c|c|}
\hline & REAM & Goal & Origin & Level of detail ${ }^{(1)}$ & Universality \\
\hline \multirow{6}{*}{$\sum_{i=1}^{n}$} & HORA & Standardization & Both & Detailed & Regional/National \\
\hline & RATL & Facilitation & Practice & Detailed & General \\
\hline & CAUDIT & Standardization & Both & Detailed & Regional/National \\
\hline & TIER & Facilitation & Practice & Semi-detailed & General \\
\hline & CLOUD & Facilitation & Academia & Aggregated & General \\
\hline & NOR-EA & Standardization & Practice & Aggregated & Regional/National \\
\hline \multirow{14}{*}{$\sum_{2}$} & UCISA & Standardization & Practice & Detailed & Regional/National \\
\hline & $\mathrm{CHE}^{2} \mathrm{~A}$ & Standardization & Both & Semi-detailed & Regional/National \\
\hline & CSU-BPM & Facilitation & Practice & Detailed & Particular \\
\hline & HE-IUP & Facilitation (2) & Both & Semi-detailed & General \\
\hline & BPRM-HE & Standardization (2) & Academia & Aggregated & General \\
\hline & HE-ISC & Standardization (2) & Practice & Aggregated & Regional/National \\
\hline & ICOPER & Facilitation & Both & Detailed & General \\
\hline & UISRM-HE & Facilitation & Academia & Semi-detailed & General \\
\hline & eEdSF & Standardization (2) & Academia & Aggregated & General \\
\hline & UTAD-ISA & Facilitation ${ }^{(2)}$ & Academia & Semi-detailed & Particular \\
\hline & RMIS-ICM & Standardization ${ }^{(2)}$ & Academia & Aggregated & General \\
\hline & RPMS-HE & Standardization ${ }^{(2)}$ & Academia & Aggregated & General \\
\hline & VC-HE & Standardization (2) & Academia & Aggregated & General \\
\hline & UNITA & Facilitation ${ }^{(2)}$ & Academia & Aggregated & General \\
\hline
\end{tabular}

${ }^{(1,2)}$ Mostly based on the authors appreciation after analysing sources found

We concentrate now (see Table 2) on the particular level of the attributes considered by the framework. With regard to the general scope attributes, our analysis reveals a relatively good balance in terms of the goal and the origin of the artefacts. Unfortunately, the identification of REAMs goals and their associated target audience becomes sometimes difficult, as developers do not tend to explicitly state it. Also, a tendency towards academic-oriented RMs as well as a great heterogeneity in the detail level of the uncovered REAMs can be appreciated. Finally, we also detect a pattern regarding the articulation of some kind of (public) HE sector-oriented interoperability initiatives, grounding on the establishment of a common abstract national REAM (for example, HORA in the Nederlands, NOR-EA in Norway or $\mathrm{CHE}^{2} \mathrm{~A}$ in Colombia). Such reference models need to be next adopted and conveniently instantiated by each HE institution, according to its own context. On the one hand, institutions could benefit of positive economic effects derived from decreasing costs due to model reusability, shortest life-cycle modelling times for developing solution EAs or an increase of the quality of EA models (Olsen and Trelsgård, 2016; Timm, 2018). On the other hand, administrations could benefit from costs reductions due to economies of scale and resource sharing - IS shared service provision across all HE. All these benefits, may justify the economic investments devoted to the REAM's conception. 
In terms of content and structure attributes (see Table 3), we detect a lack of artefacts addressing technology-oriented issues, as we only were able to find 4 REAMs addressing these in some way. This finding can be considered as consistent with the existing literature on EAs, in which technology domain layers tend to be considered as less application-domain dependent than others. In this sense, we also observe a notable lack of REAMs addressing business processes and activities related with the third-mission of a $\mathrm{HE}$ institution. As expected, the main focus tends to be on the teaching and learning processes as well as their respective support processes.

Table 3. Structure and Content Attributes Analysis

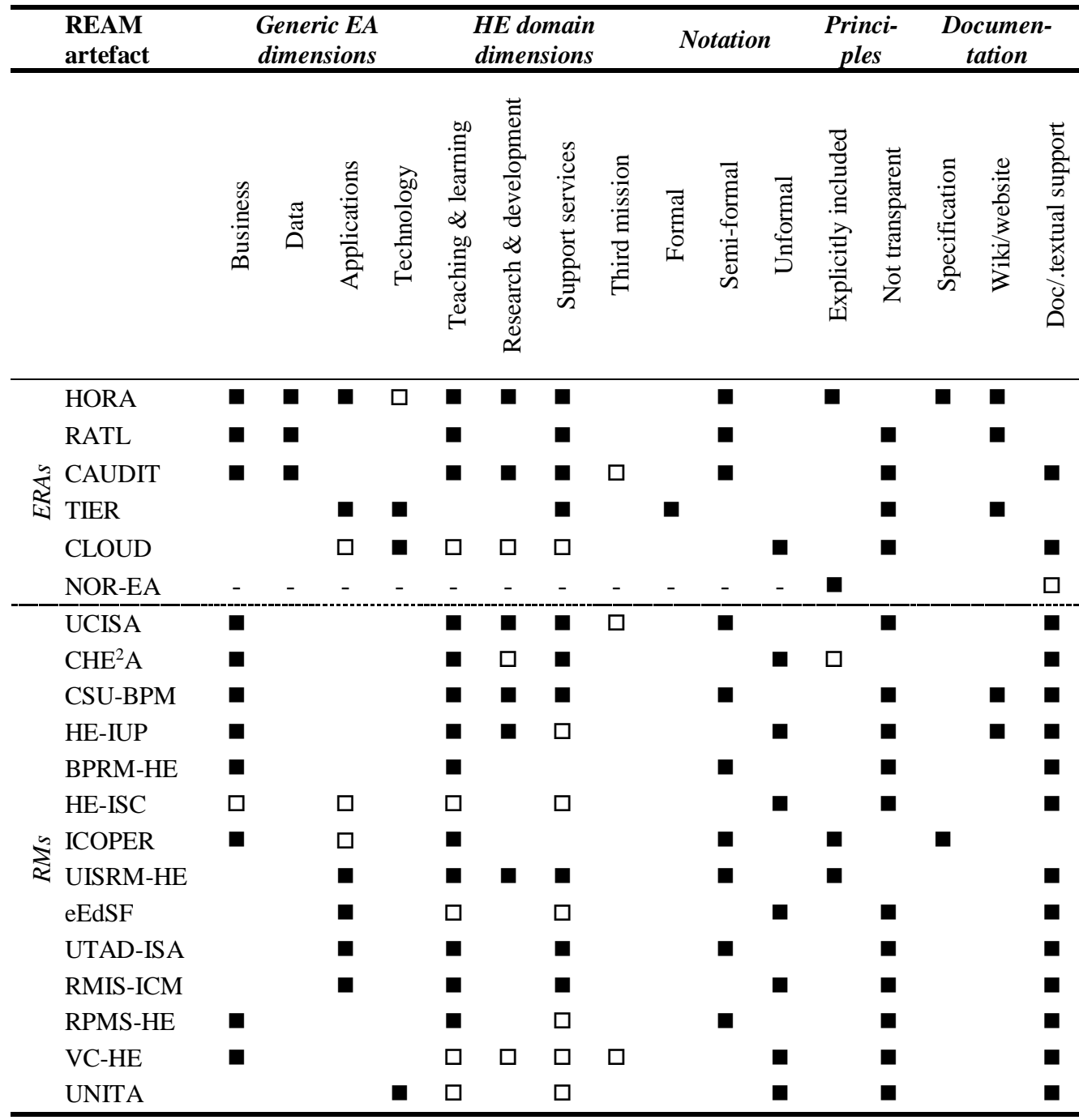

- Full coverage | $\square$ Suggested or basic coverage | - Not evaluated 
IADIS International Journal on Computer Science and Information Systems

On the other hand, architectural principles (as another key component of reference artefacts) should be much more clearly made explicit by developers of these models. A tendency towards the use of semi-formal and unformal notations is also appreciated, which should be interpreted as a sing in favour of the artefact's simplicity, facilitating their understandability by different potential HE stakeholders. Finally, as only 6 of the 19 investigated models have either a dedicated web/wiki page or are alternatively disseminated through a formal specification report, we interpret the availability of detailed documentation of a REAM as a certain sign of rigor in the process development of the artefact.

Lastly, and in terms of practical use attributes (see Table 4), our analysis reveals a notable lack of support of the investigated artifacts in terms of applicability. We believe that there is a clear need for developing more easily applicable and practice-oriented REAMs for HE, providing more additional details on how and why to apply them.

On the other hand, we also appreciate a general lack of evidences for testing or demonstrating the utility and value of such abstract artifacts in real scenarios, even in those cases being originated from practice. In this sense, several of those REAMs are no more than just simple and basic descriptive conceptual models. In this line, developing REAMs for HE in a more transparent and scientifically theoretically-sound procedure would help in providing more empirical evidence on the value of such models. We must highlight at this point, however, that in those cases in which the REAM is developed through joint collaborative efforts (consortiums) engaging a great number of representative stakeholders and participating organizations involved in the HE industry itself - as for the case of HORA, CAUDIT, NOR-EA RATL, TIER or even $\mathrm{CHE}^{2} \mathrm{~A}$ - it should be considered that their reliability and universality is implicitly validated by all those key users and stakeholders involved in the consortium's development teams.

Table 4. Practical Use Attributes Analysis

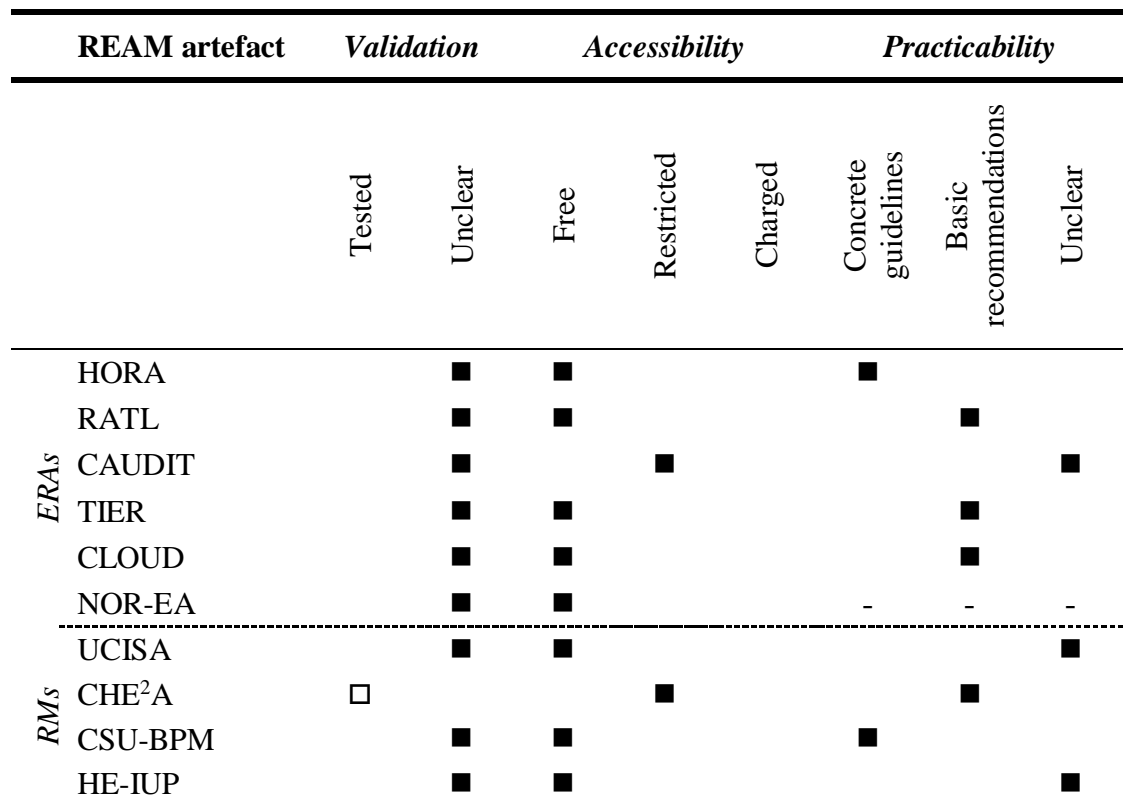




\begin{tabular}{|c|c|c|c|c|c|c|c|c|}
\hline \multirow[t]{2}{*}{ REAM artefact } & \multicolumn{2}{|c|}{ Validation } & \multicolumn{3}{|c|}{ Accessibility } & \multicolumn{3}{|c|}{ Practicability } \\
\hline & 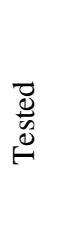 & $\begin{array}{l}\frac{\vec{\Xi}}{\mathscr{U}} \\
\underline{\Xi}\end{array}$ & 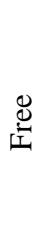 & 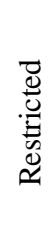 & $\begin{array}{l}\vec{D} \\
\dot{0} \\
\bar{\Xi} \\
\text { U }\end{array}$ & 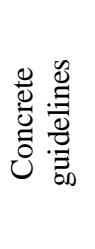 & 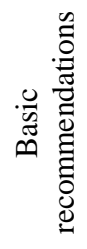 & $\frac{\mathscr{J}}{\stackrel{\Xi}{\Xi}}$ \\
\hline BPRM-HE & & 口 & $\square$ & & & & & 口 \\
\hline HE-ISC & & ש & 口 & & & & & 口 \\
\hline ICOPER & 口 & & 口 & & & घ & & \\
\hline UISRM-HE & & घ & 口 & & & & & 口 \\
\hline eEdSF & & घ & 口 & & & & & 口 \\
\hline UTAD-ISA & & घ & 口 & & & & & 口 \\
\hline RMIS-ICM & & 口 & 口 & & & & & 口 \\
\hline RPMS-HE & $\square$ & & 口 & & & 口 & & \\
\hline VC-HE & & - & 口 & & & & & 口 \\
\hline UNITA & & घ & 口 & & & & & 口 \\
\hline
\end{tabular}

Finally, we note that nearly all the investigated models are freely accessible, but CAUDIT's RA use is restricted by a creative commons license. Whilst this finding may seem up to a point surprising, the social nature inherent to HE should be considered here. Under this context, we understand that REAMs are not produced to be monetarized by means of payment fees or usage licenses. Contrarily, they are poised to benefit to as many as possible HE institutions (and interested) parties through their effective application in practice - they are a means, not a goal in themselves-. Hence, their simplicity and understandability should be promoted to the maximum extent.

\section{CONCLUSION}

In this paper, we set out to examine the status-quo of REAMs targeted to the HE domain. Based on a series of attributes characterizing their general scope, structure, content and practical use, we have proposed both the process and its application to critically review in a comparative style a total of 20 existing abstract models. This aims to be a primer approach for in-depth analysis, review, comparison and classification, since new attributes may be considered in future extensions. For example, an additional quality dimension might be considered in order to evaluate the support offered by the investigated REAMs in terms of integrity, security, maintainability or even scalability. Further research should also be focalized on providing additional empirical evidence on the utility and value of REAMs in real HE contexts. Finally, the subjectivity on the attributes considered for analysis as well as the particular evaluation granted by the authors to each of them may be considered as a limitation of the paper. 


\section{ACKNOWLEDGEMENT}

This work is supported by the Industrial Doctorates Program of the Generalitat de Catalunya (2014 DI 077).

\section{REFERENCES}

Abel, R., Brown, M. and Suess, J. (2013). A New Architecture for Learning. EDUCAUSE Review, Vol. 48 No. 5, pp. 88-102.

Aljlayel, N. (2016). Holistic Enterprise Architecture Frameworks (HEAFs). Trends in Applied Sciences Research, Vol. 11 No. 2, pp. 33-43.

Alwadain, A., Fielt, E., Korthaus, A. and Rosemann, M. (2013). A Comparative Analysis of the Integration of SOA Elements in Widely-Used Enterprise Architecture Frameworks. International Journal of Intelligent Information Technologies, Vol. 9 No. 2, pp. 54-70.

Anderson, I. (n.d.). UK HE Capability Model, UCISA. Available at: https://www.ucisa.ac.uk/ representation/activities/cap_model (accessed 14 October 2018).

Angelov, S., Grefen, P. and Greefhorst, D. (2012). A framework for analysis and design of software reference architectures. Information and Software Technology, Vol. 54 No. 4, pp. 417-431.

Barata, J. and Cunha, P.R. (2017). Synergies between quality management and information systems: a literature review and map for further research. Total Quality Management \& Business Excellence, Vol. 28 No. 3-4, pp. 282-295.

Bergh-Hoff, H., Sørensen, C.-F., Garshol, J.E., Jakobsen, B.H.M., Vangen, G.M., Pettersen, Ø.D. and Hansen, J. (2015). ICT Architecture Principles for the Norwegian Higher Education Sector, September 3, 2015. Uninett. Available at: https://www.uninett.no/sites/default/files/ict_architectural_principles. pdf.

Bessa, J., Branco, F., Costa, A., Martins, J. and Goncalves, R. (2016). A multidimensional information system architecture proposal for management support in Portuguese Higher Education: The University of Tras-os-Montes and Alto Douro case study [In Portuguese]. 11th Iberian Conference on Information Systems and Technologies (CISTI 2016). Gran Canaria, Canary Islands, Spain, June 15-18, pp. 1-7.

Bick, M. and Börgmann, K. (2009). A Reference Model for the Evaluation of Information Systems for an Integrated Campus Management. International Conference EUNIS 2009. Santiago de Compostela, Spain, June 23-26. Available at: http://www.immagic.com/eLibrary/ARCHIVES/GENERAL/ EUNIS_FR/E090625C.pdf.

Bischoff, S., Aier, S. and Winter, R. (2014). Use It or Lose It? The Role of Pressure for Use and Utility of Enterprise Architecture Artifacts. Proceedings of the 16th IEEE Conference on Business Informatics, Vol. 2. Los Alamitos, CA, United States : IEEE Computer Society, 2014, pp. 133-140.

de Boer, R., Schijvenaars, T. and Oord, E. (2011). Referentiearchitecturen in de praktijk. Delen van architectuurkennis in een stelsel van semantische wiki's [In Dutch]. Via Nova Architectura Magazine, Vol. October 2011, pp. 1-14.

Bonnie, P. and Obitz, T. (2013). Integrating the TOGAF® Standard with the BIAN Service Landscape, The Banking Industry Architecture Network and the Open Group. Available at https://static.bian.org/wp-content/uploads/2013/10/wp_togaf_bian_version-2-0-final1.pdf (accessed 20 April 2017).

Campbell, D. and Carayannis, E.G. (2016). Epistemic governance and epistemic innovation policy in higher education. Technology, Innovation and Education, Vol. 2 No. 1, pp. 1 - 15. 
CAUDIT. (2016). Enterprise Architecture Commons for Higher Education, CAUDIT. Council of Australian University Directors of Information Technology. Available at: https://www.caudit.edu.au /EA-Framework (accessed 28 March 2017).

CAUDIT (2017). CAUDIT Higher Education EA Reference models roll out to 147 universities - and counting!, CAUDIT. Council of Australian University Directors of Information Technology. Available at: $\quad$ https://www.caudit.edu.au/news/caudit-higher-education-ea-reference-models-roll-out-147universities-and-counting (accessed 7 September 2017).

Charles Sturt University (2010). Higher Education Process Reference Model, Charles Sturt University Work Process Improvement. Available at: http://www.csu.edu.au/special/wpp/resources/referencemodel.

Chen, S., Tang, Y. and Li, Z. (2016). UNITA: A Reference Model of University IT Architecture. Proceedings of the 2016 International Conference on Communication and Information Systems. Bangkok, Thailand, December 16 - 18, 2016, pp. 73-77.

Cloutier, R., Muller, G., Verma, D., Nilchiani, R., Hole, E. and Bone, M. (2010). The Concept of Reference Architectures, Systems Engineering, Vol. 13 No. 1, pp. 14-27.

Czarnecki, C. and Dietze, C. (2017). Designing the architecture solution, Reference Architecture for the Telecommunications Industry. Transformation of Strategy, Organization, Processes, Data, and Applications, Springer International Publishing, pp. 103-202.

Department of Defense. (2010). DoD Reference Architecture Description, Office of the Department of Defense CIO, USA, Tech. Rep., 2010, pp. 1-20.

E-Overheid. (2010). NORA's Strategy Supplement. The Hague, Netherlands.

Fagan, M.H. (2003). Exploring e-education applications: a framework for analysis, Campus-Wide Information Systems, Vol. 20 No. 4, pp. 129-136.

Fettke, P. and Loos, P. (Eds.). (2007). Reference Modeling for Business Systems Analysis, IGI Global.

Fettke, P., Loos, P. and Zwicker, J. (2006). Business Process Reference Models: Survey and Classification. In Bussler, C.J. and Haller, A. (Eds.), Business Process Management Workshops: BPM 2005 International Workshops, BPI, BPD, ENEI, BPRM, WSCOBPM, BPS, Nancy, France, September 5, 2005. Revised Selected Papers, Springer Berlin Heidelberg, Berlin, Heidelberg, pp. 469-483.

Frackmann, E. (2007). Higher Education Information Systems. Proposal for an Overall Concept for Higher Education Information Systems in Croatia. Agency of Science and Higher Education, Croatia, pp. 1-14.

Greefhorst, D., Koning, H. and Vliet, H. van. (2006). The many faces of architectural descriptions, Information Systems Frontiers, Vol. 8 No. 2, pp. 103-113.

ten Harmsen van der Beek, W., Trienekens, J. and Grefen, P. (2012). The Application of Enterprise Reference Architecture in the Financial Industry, in Aier, S., Ekstedt, M., Matthes, F., Proper, E. and Sanz, J.L. (Eds.). TEAR 2012 and PRET 2012 Proceedings, Springer Berlin Heidelberg, Berlin, Heidelberg, pp. 93-110.

Huschens, J. and Rumpold-Preining, M. (2006). IBM Insurance Application Architecture (IAA) - An overview of the Insurance Business Architecture. In Bernus, P., Mertins, K. and Schmidt, G. (Eds.) Handbook on Architectures of Information Systems, Springer Berlin Heidelberg, Berlin, Heidelberg, pp. 669-692.

Hutaibat, K.A. (2011). Value Chain for Strategic Management Accounting in Higher Education. International Journal of Business and Management, Vol. 6 No. 11, pp 206-218.

ITANA Working Group. (2012). Reference Architecture for Teaching and Learning, ITANA Wiki, Available at: https://spaces.internet2.edu/display/itana/Reference+Architecture+for+Teaching +and+ Learning (accessed 3 June 2018).

JISC. (2009). Doing Enterprise Architecture : Enabling the Agile Institution, No. 533, Version 1.1 March 2009. Available at:/http://www.jisc.ac.uk/media/documents/techwatch/jisc_ea_pilot_study.pdf. 
IADIS International Journal on Computer Science and Information Systems

Kotusev, S., Singh, M. and Storey, I. (2015). Investigating the usage of enterprise architecture artifacts. Proceedings of the Twenty Third European Conference on Information Systems (ECIS 2015). Münster, Germany, May 26-29, 2015, pp. 1-12.

Kotzampasaki, M. (2015). Design of a Process for the Selection of an Enterprise Reference Architecture (Master Thesis). Technische Universiteit Eindhoven, Eindhoven. Available at: http://repository.tue.nl/ 5a6b604a-0a72-4465-99d1-a3758565f328.

Lankhorst, M. (2014). The Value of Reference Architectures. Bizzdesign Blog. Available at: http://blog.bizzdesign.com/the-value-of-reference-architectures (accessed 20 May 2017).

Llamosa-Villalba, R., Carreño, L.T., Paez, Q.A.M., Delgado, Q.D.J., Barajas, A.B. and Sneyder, E.G. (2015). Enterprise architecture of Colombian Higher Education. 2015 IEEE Frontiers in Education Conference (FIE). El Paso, TX, USA, 21-24 October 2015, pp. 1-9.

Llamosa-Villalba, R., Delgado, D.J., Camacho, H.P., Paéz, A.M. and Valdivieso, R.F. (2014). Organizational Leadership Process for University Education. 11th International Conference on Cognition and Exploratory Learning in Digital Age (CELDA 2014). Porto, Portugal, 25 - 27 October 2014, pp. 119-126.

Luftman, J. and Kempaiah, R. (2007). An Update on Business-IT Alignment: A Line Has Been Drawn, MIS Quarterly Executive, Vol. 6 No. 3, pp. 165-177.

Luftman, J.N., Bullen, C.V., Liao, D. and Neumann, C. (2004). Managing Information Technology Resource. Leadership in the Information Age, Pearson Education Inc., Upper Saddle River, NJ.

Magoulas, T., Hadzic, A., Saarikko, T. and Pessi, K. (2012). Alignment in enterprise architecture: A comparative analysis of four architectural approaches. Electronic Journal Information Systems Evaluation, Vol. 15 No. 1, pp. 88-101.

Manatos, M.J., Sarrico, C.S. and Rosa, M.J. (2017). The integration of quality management in higher education institutions: a systematic literature review. Total Quality Management \& Business Excellence, Vol. 28 No. 1-2, pp. 159-175.

Masuda, Y., Shirasaka, S. and Yamamoto, S. (2016). Integrating Mobile IT/Cloud into Enterprise Architecture: A Comparative Analysis. Proceedings of the 20th Pacific Asia Conference on Information Systems (PACIS 2016). Chiayi, Taiwan, June 27 - July 12016.

Mettler, T. (2011). Maturity assessment models: a design science research approach. International Journal of Society Systems Science, Vol. 3 No. 1-2, pp. 81-98.

Ministry of Defence. (2013). MODAF M3 Version 1.2.004, Ministry of Defence, UK, 2013. Available at: https://www.gov.uk/government/uploads/system/uploads/attachment_data/file/63979/20130117_MO DAF_M3_version1_2_004.pdf.

Mircea, M. and Andreescu, A.I. (2011). Using Cloud Computing in Higher Education: A Strategy to Improve Agility in the Current Financial Crisis. Communications of the IBIMA, pp. 1-15.

Nakagawa, E.Y., Oquendo, F. and Maldonado, J.C. (2014). Reference Architectures, in Chabane Oussalah, M. and Pomerol, J.-C. (Eds.). Software Architecture. John Wiley \& Sons, Inc., Hoboken, NJ, USA, pp. 55-82.

Niemi, E. and Pekkola, S. (2017). Using enterprise architecture artefacts in an organisation, Enterprise Information Systems, Vol. 11 No. 3, pp. 313-338.

Oderinde, D. (2010). Using Enterprise Architecture (EA) as a Business-IT Strategy Alignment for Higher Educational Institutions (HEIs). Proceedings of UK Academy for Information Systems (UKAIS Conference. Oriel College, Oxford, UK, pp. 1-10.

Olsen, D.H. and Trelsgård, K. (2016). Enterprise Architecture Adoption Challenges: An exploratory Case Study of the Norwegian Higher Education Sector. Procedia Computer Science, Vol. 100 No. 2016, pp. 804-811.

Pajk, D., Indihar-Štemberger, M. and Kovapip, A. (2012). Reference Model Design: An Approach and its Application. Proceedings of the $34^{\text {th }}$ International Conference on Information Technology Interfaces. Cavtat, Croatia, June 25-28, 2012, pp. 455-460. 
Pang, G. (2015). Reference Architecture Models with ArchiMate. Bizzdesign Blog. Available at: blog.bizzdesign.com/reference-architecture-models-with-archimate.

Pardeshi, V.H. (2014). Cloud Computing for Higher Education Institutes: Architecture, Strategy and Recommendations for Effective Adaptation. Procedia Economics and Finance, Vol. 11, pp. 589-599.

Pawlowski, J.M. and Kozlov, D. (2013). Analysis and Validation of Learning Technology Models, Standards and Specifications: The Reference Model Analysis Grid (RMAG). In Jakobs, K. (Ed.) Innovations in Organizational IT Specification and Standards Development. IGI Global, pp. 223-240.

Purao, S., Martin, R. and Robertson, E. (2011). Transforming Enterprise Architecture Models: An Artificial Ontology View. In Mouratidis, H. and Rolland, C. (Eds.). CAiSE 2011 Proceedings, LNCS 6741, Vol. 6741, Springer Berlin Heidelberg, pp. 383-390.

Reiner, M. (2014). Improvement of Business Process Management in Higher Education Institutions. Education, Audiovisual \& Culture Executive Agency (EAC-EA). Final report. Available at: http://eacea.ec.europa.eu/LLp/project_reports/documents/erasmus/ECUE/eras_ecue_518035_fr.pdf (accessed 28 March 2017).

Riihimaa, J. (2009). Combining Enterprise Architecture and Quality Assurance System from Data Administration Viewpoint. International Conference EUNIS 2009. Santiago de Compostela, Spain, June $23^{\text {rd }}-26$ th, 2009.

Rouhani, B.D., Mahrin, M.N., Nikpay, F. and Nikfard, P. (2013). A comparison enterprise architecture implementation methodologies. Proceedings of the 2013 International Conference on Informatics and Creative Multimedia. Kuala Lumpur, Malaysia, 4-6 September 2013, pp. 1-6.

Sanchez-Puchol, F. and Pastor-Collado, J.A. (2017). A First Litrature Review on Enterprise Reference Architectures. Proceedings of the 11th Mediterranean Conference on Information Systems (MCIS). Genova, Italy, 4-5 September 2017, pp. 1-12.

Sanchez-Puchol, F., Pastor-Collado, J.A. and Borrell, B. (2017). Towards an Unified Information Systems Reference Model for Higher Education Institutions. Procedia Computer Science, Vol. 121, pp. 542 553.

Sanchez-Puchol, F., Pastor-Collado, J.A. and Borrell, B. (2018). A Critical Review on Reference Architectures and Models for Higher Education Institutions. $7^{\text {th }}$ International Conference on Theory and Practice in Modern Computing (MCCIS 2018). Madrid, Spain, 17-20 ${ }^{\text {th }}$ July, 2018.

Simon, B., Pulkkinen, M., Totschnig, M. and Kozlov, D. (2011). The ICOPER Reference Model for Outcome-Based Higher Education, No. ECP 2007 EDU 417007, eContentplus, July 2011, pp. $1-168$.

SURF. (2013a). Hoger Onderwijs Referentie Architectuur [In Dutch]. Hoger Onderwijs Referentie Architectuur. Available at: https://hora.surf.nl/index.php/Hoger_Onderwijs_Referentie_Architectuur (accessed 28 May 2018).

SURF. (2013b). Hoger Onderwijs Referentie Architectuur. Referentiemodellen [In Dutch]. SURF, Project Regie in de Cloud. Versie 1.0. Available at: https://www.surf.nl/binaries/content /assets/surf/nl/kennisbank/2013/HORA_Referentiemodellen.pdf (accessed 28 March 2017).

SURF. (2013c). Hoger Onderwijs Referentie Architectuur. Implementatiehulpmiddelen [In Dutch]. SURF, Project Regie in de Cloud. Versie 1.0. Available at: https://www.surf.nl/binaries/ content/assets/surf/nl/kennisbank/2013/HORA_Implementatiehulpmiddelen.pdf (accessed 28 May 2018).

Svensson, C. and Hvolby, H.-H. (2012). Establishing a Business Process Reference Model for Universities, Procedia Technology, Vol. 5 No. 2012, pp. 635-642.

Syynimaa, N. (2015). Modeling the Dynamics of Enterprise Architecture Adoption Process. In Hammoudi, S., Maciaszek, L., Teniente, E., Camp, O. and Cordeiro, J. (Eds.). Enterprise Information Systems, Springer International Publishing, Cham, pp. 577-594. 
IADIS International Journal on Computer Science and Information Systems

Tang, A., Han, J. and Chen, P. (2004). A comparative analysis of architecture frameworks. 11th AsiaPacific Software Engineering Conference (APSEC 2014). Busan, South Korea, 30 Nov - 3 Dec. 2004, pp. 640-647.

Thomas, O. (2006). Understanding the Term Reference Model in Information Systems Research: History, Literature Analysis and Explanation. In Bussler, C.J. and Haller, A. (Eds.). Business Process Management Workshops, Springer Berlin Heidelberg, Berlin, Heidelberg, pp. 484-496.

TIER-Data Structures and APIs Working Group (2016). The TIER Reference Architecture (RA). Available at: https://spaces.internet2.edu/pages/viewpage.action?pageId=98306902 (accessed 1 April 2017).

Timm, F. (2018). An Application Design for Reference Enterprise Architecture Models. In Matulevičius, R. and Dijkman, R. (Eds.). Advanced Information Systems Engineering Workshops, Springer International Publishing, Cham, pp. 209-221.

Timm, F., Hacks, S., Thiede, F. and Hintzpeter, D. (2017). Towards a Quality Framework for Enterprise Architecture Models. Proceedings of the 5th International Workshop on Quantitative Approaches to Software Quality (QuASoQ 2017), Co-Located with APSEC 2017. Nanjing, China, December 4, 2017, pp. 14-21.

UCISA (2018). Launch of the UK HE Capability Model. UCISA, Web Portal. Available at: https://www.ucisa.ac.uk/news/2018-03_15_capmodel (accessed 14 October 2018).

Urbaczewski, L. and Mrdalj, S. (2006). A Comparison of Enterprise Architecture Frameworks. Issues in Information Systems, Vol. 2 No. 2, pp. 18-23.

Van der Merwe, A.J. (2005). Towards a Reusable Process Model Structure for Higher Education Institutions (Doctoral Thesis). University of South Africa. Available at: http://uir.unisa.ac.za/ bitstream/handle/10500/653/ 00thesis.pdf?sequence $=5$.

Winter, R. and Fischer, R. (2007). Essential Layers, Artifacts, and Dependencies of Enterprise Architecture. Journal of Enterprise Architecture, Vol. 3 No. 2, pp. 7-18. 